\title{
Maxillary Interdental Osteotomies Have Low Morbidity for Alveolar Crestal Bone and Adjacent Teeth: A Cone Beam Computed Tomography-Based Study
}

\author{
Daniel B. Rodrigues, DDS, ${ }^{\star}$ Paulo S. F. Campos, DDS, PhD, $\dagger$ Larry M. Wolford, DMD, $\neq$ \\ Jaqueline Ignácio, DDS, $\S$ and João R. Gonçalves, DDS, PbD\|
}

\begin{abstract}
Purpose: Maxillary segmentation involving interdental osteotomies can have an adverse effect on the interdental crestal bone and adjacent teeth. The purpose of the present study was to evaluate the effect of interdental osteotomies on surrounding osseous and dental structures, including adjacent teeth, using cone beam computed tomography (CBCT), in patients who underwent segmental maxillary osteotomies.

Patients and Methods: The present retrospective cohort study evaluated interdental osteotomy (IDO) sites between the lateral incisors and canines in patients treated with 3-piece Le Fort I osteotomies. CBCT scans were assessed using Kodac Dental Imaging software at specific intervals: T0 (before surgery), T1 (immediately after surgery), and T2 (a minimum of 11 months after surgery). The statistical analysis using a linear regression model was adjusted to compare the variables at the different intervals. Injury to the dental structures was assessed by radiological evidence of dental damage, the requirement for endodontic treatment, or tooth loss.
\end{abstract}

Results: We evaluated 94 IDO sites in 47 patients in the present study. The mean inter-radicular distance at T0 was $2.5 \mathrm{~mm}$. A statistically significant increase was seen in the inter-radicular distance (between T1 and T0) of $0.72 \mathrm{~mm}$, with a reduction of the alveolar bone crest height (between T2 and T0) of $0.19 \mathrm{~mm}(P<.001)$ for the group that underwent IDO. A weak correlation was found for this increase in the inter-radicular distance, with changes in the alveolar crest bone height. The potential complications associated with interdental osteotomies such as iatrogenic damage to the tooth structure, the need for endodontic treatment, and tooth loss were not encountered in any patients.

Conclusions: We found very low morbidity for the interdental alveolar crest and the integrity of teeth adjacent to interdental osteotomies for patients who underwent maxillary segmentation between the lateral incisors and canines.

(C) 2018 American Association of Oral and Maxillofacial Surgeons

J Oral Maxillofac Surg 76:1763-1771, 2018

*Clinical Professor, Residency of Oral and Maxillofacial Surgery, Federal University of Bahia, and Private Practice, Salvador, BA, Brazil.

$\nmid$ Professor, Department of Oral and Maxillofacial Radiology, Federal University of Bahia, School of Dentistry, Salvador, BA, Brazil.

$\ddagger$ Clinical Professor, Department of Oral and Maxillofacial Surgery, Texas A\&M University College of Dentistry, Baylor University Medical Center, Dallas, TX.

$\S$ Postgraduate Student, Department of Pediatric Dentistry, Araraquara Dental School, State University of São Paulo, Araraquara, SP, Brazil.

| |Clinical Professor, Department of Pediatric Dentistry, Araraquara Dental School, State University of São Paulo, Araraquara, SP, Brazil.
Conflict of Interest Disclosures: None of the authors have any relevant financial relationship(s) with a commercial interest.

Address correspondence and reprint requests to Dr Wolford: 3409 Worth Street, Suite 400, Dallas, TX 75246; e-mail: 1wolford@ swbell.net

Received March 122017

Accepted January 292018

(C) 2018 American Association of Oral and Maxillofacial Surgeons

0278-2391/18/30111-3

https://doi.org/10.1016/i.joms.2018.01.031 
Maxillary interdental osteotomy (IDO) for segmentation of the maxilla can be combined with other osteotomies to achieve a better esthetic and occlusal result in the treatment of dentofacial deformities. ${ }^{1}$ IDO can be indicated to correct a maxillary transverse deficiency, curve of Spee, anterior open bite, ${ }^{2-4}$ anterior alveolar protrusion, excessive spaces between segments, tooth size discrepancies, and inclination of the incisors. ${ }^{5}$

The most common sites for performance of the maxillary IDO are between the lateral incisors and canines and between the canines and premolars. ${ }^{6}$ The orthodontic preparation for IDO requires root divergence of the adjacent teeth to prevent dental injuries from the burs, osteotomies, and other instruments used for the surgery. ${ }^{7}$

The complications associated with maxillary IDOs include loss of a tooth, tooth mobility, jaw mobility, a periodontal defect, oroantral fistula, and jaw necrosis. ${ }^{3}$ Nevertheless, a recent review of hospital admissions for orthognathic surgery in the United States found that the maxillary segmentation is a commonly performed procedure ( $45.8 \%$ of cases). ${ }^{8}$ Despite this relative frequency, some resistance still exists from orthodontists and oral-maxillofacial surgeons to perform segmental surgery. The major concerns are periodontal complications and the loss of teeth associated with the IDO region. The prevalence of morbidity is related to the preoperative inter-radicular distance and increased interdental distance during the surgical procedure and excessive trauma, resulting in soft and hard tissue injury during the procedure.

We sought to determine whether IDOs have an adverse effect on the alveolar bone and adjacent teeth. Our hypothesis was that IDOs will have a minimal adverse effect on these structures. The aims of our study were to define a safe distance between the roots of the teeth adjacent to the osteotomy site and to evaluate the changes in alveolar bone crest height and the integrity of the adjacent teeth in patients who underwent 3-piece maxillary segmentation with IDOs between the lateral incisors and canines compared with patients with Le Fort I osteotomies without segmentation. We used data from cone beam computed tomography (CBCT) scans to evaluate the 2 groups.

\section{Patients and Methods}

We designed a retrospective cohort study. The sample included the CBCT scans of all consecutive patients with dentofacial deformities who had undergone surgery by 1 surgeon (L.M.W.) at Baylor University Medical Center (Dallas, TX), from November 2008 to January 2013. The institutional review board approved the present study (Faculdade de Odontologia de Araraquara, CAAE: 01032912.2.0000.5416).
All the patients included in the present study signed an informed consent form for hospital admission, surgical procedures, and release of information for research purposes. To be included in the study sample, patients had to meet the following inclusion criteria: 1) Le Fort I osteotomy without maxillary segmentation; 2) Le Fort I osteotomy with IDO for maxillary segmentation between lateral incisors and canines; 3) a series of CBCT scans taken before surgery (T0), immediately after surgery (T1), and a minimum of 11 months after surgery (T2); and 4) aged at least 15 years for females and at least 17 years for males. The exclusion criteria were 1) cleft lip and palate; 2) endodontic treatment before surgery on the teeth adjacent to the osteotomy site; 3) a history of pre- and postoperative trauma to the teeth adjacent to the osteotomy site; 4) incomplete records; and/or 5) patient refusal to participate in the study.

In the present study, the changes in the interdental crestal bone height and integrity of the teeth at the IDO area were the outcome variables. The predictor variables were the type of surgery, changes in the inter-radicular distance, and the interval between T0 and T2. Others variable of interest such as gender and age were considered.

\section{SURGICAL PROCEDURE}

The maxillary surgical procedures were completed as follows. A circumvestibular incision was made above the mucogingival junction, from the first molar to first molar. A Le Fort I procedure was performed, including a horizontal osteotomy with the maxillary step design from the piriform rim to the pterygoid region. ${ }^{9,10}$ A curved osteotome was used to separate the pterygoid plates from the tuberosity of the maxilla. The arch wire was sectioned between the lateral incisor and canine. Using a no. 9 periosteal elevator, a mucogingival tunnel was carefully created along the proposed IDO site. The papilla was not elevated. A no. 699 tapered fissure burr was used to perform a vertical monocortical bone cut between the adjacent roots, and a thin spatula osteotome was used to complete the osteotomy through the palatal cortical plate. The Le Fort I downfracture was then completed in the standard fashion. A parasagittal palatal mucoperiosteal incision ${ }^{7}$ with undermining of the palatal mucoperiosteum was performed, followed by a midline palatal osteotomy with a reciprocating bone saw. Bilateral anterior palatal cuts were then performed to connect with the vertical IDOs to complete the segmentation. This palatal parasagittal incision decreases the tension in the palatal soft tissues and accommodates the bony maxillary expansion. The segments were then mobilized and placed into position using a palatal splint. ${ }^{7}$ The maxilla was then stabilized 
in its new position using rigid internal fixation with bone plates. Any significant osseous defects in the IDO were grafted with autogenous bone collected from the mandible or maxilla during surgery. An alar base cinch suture and $<$ SS $>\mathrm{V}</$ SS $>-<$ SS $>\mathrm{Y}</$ SS $>$ closure of the circumvestibular incision were then completed. ${ }^{11}$ The palatal splint was usually left in place for 6 to 16 weeks, depending on the amount of maxillary expansion. A continuous maxillary arch wire was usually placed at 4 to 6 weeks after surgery.

\section{CBCT ACQUISITION AND IMAGE ANALYSIS}

Volumetric data sets were acquired with the iCAT Cone Beam 3D Imaging System (Imaging Science International, Hatfield, PA) before surgery (T0), immediately after surgery (T1), and at the longest follow-up point (T2). The patients were seated upright, with the Frankfort plane (tragus-infraorbital rim line) parallel to the ground, and were instructed to remain still, not to swallow during image acquisition, and to keep the teeth together in centric relation, with the lips relaxed. All CBCT scans were obtained with a $17 \times 23 \mathrm{~cm}$ field of view, 0.3 voxel, and 17.8-second acquisition time.

The CBCT images were reconstructed and manipulated with CS 3D Imaging Software (Carestream Health, Rochester, NY). For each IDO area, 5 variables were analyzed: bone crest height and inter-radicular distance at T0; inter-radicular distance and root damage at $\mathrm{T} 1$; and bone crest height, presence of root canal filling, and tooth loss at T2.

The measurements in each IDO area followed the following sequence. First, the software home screen oblique view window was selected. Second, in the sagittal view, a vertical line was positioned on the long axis of the canine (Fig 1). Third, in the axial view, the horizontal line was positioned through the root canal of the lateral incisor and the canine and the vertical line was placed between these 2 teeth (Fig 2). Fourth, the coronal view window was maximized, and 2 lines with a $90^{\circ}$ angle were drawn with the vertical axis passing along the axis of the canine and the horizontal axis passing through canine cementoenamel junction (Fig 3). Fifth, the height of the alveolar crest was measured in millimeters from the horizontal axis with a line parallel to the vertical axis (Fig 4). Finally, the inter-radicular distance was measured $3 \mathrm{~mm}$ above the cementoenamel junction of the canine, with a line parallel to the horizontal axis (Fig 5).

\section{Statistical Analysis}

To assess whether changes in crest height were related to the type of surgery and the time elapsed

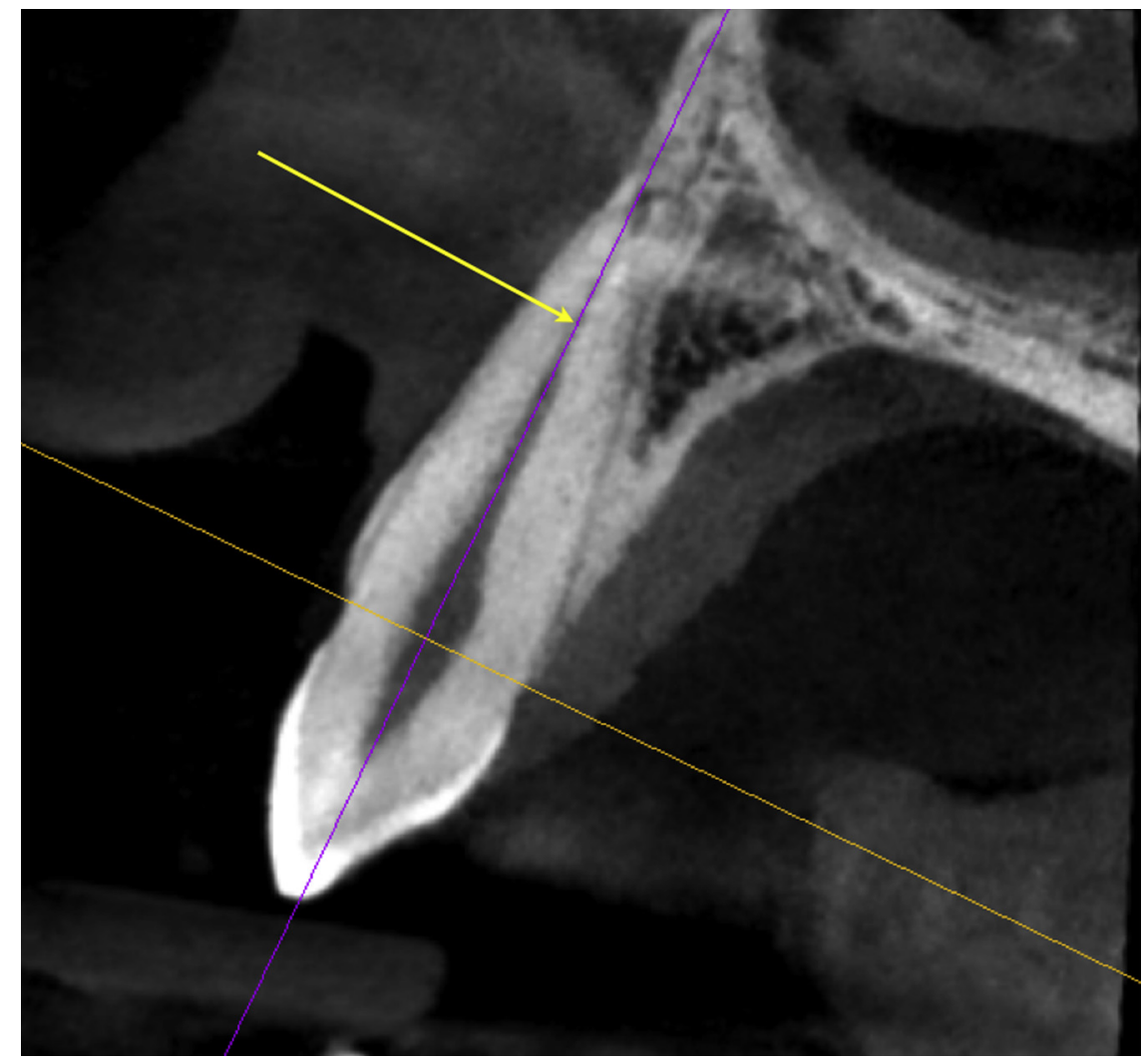

FIGURE 1. Vertical line positioned on the long axis of the canine (arrow). 


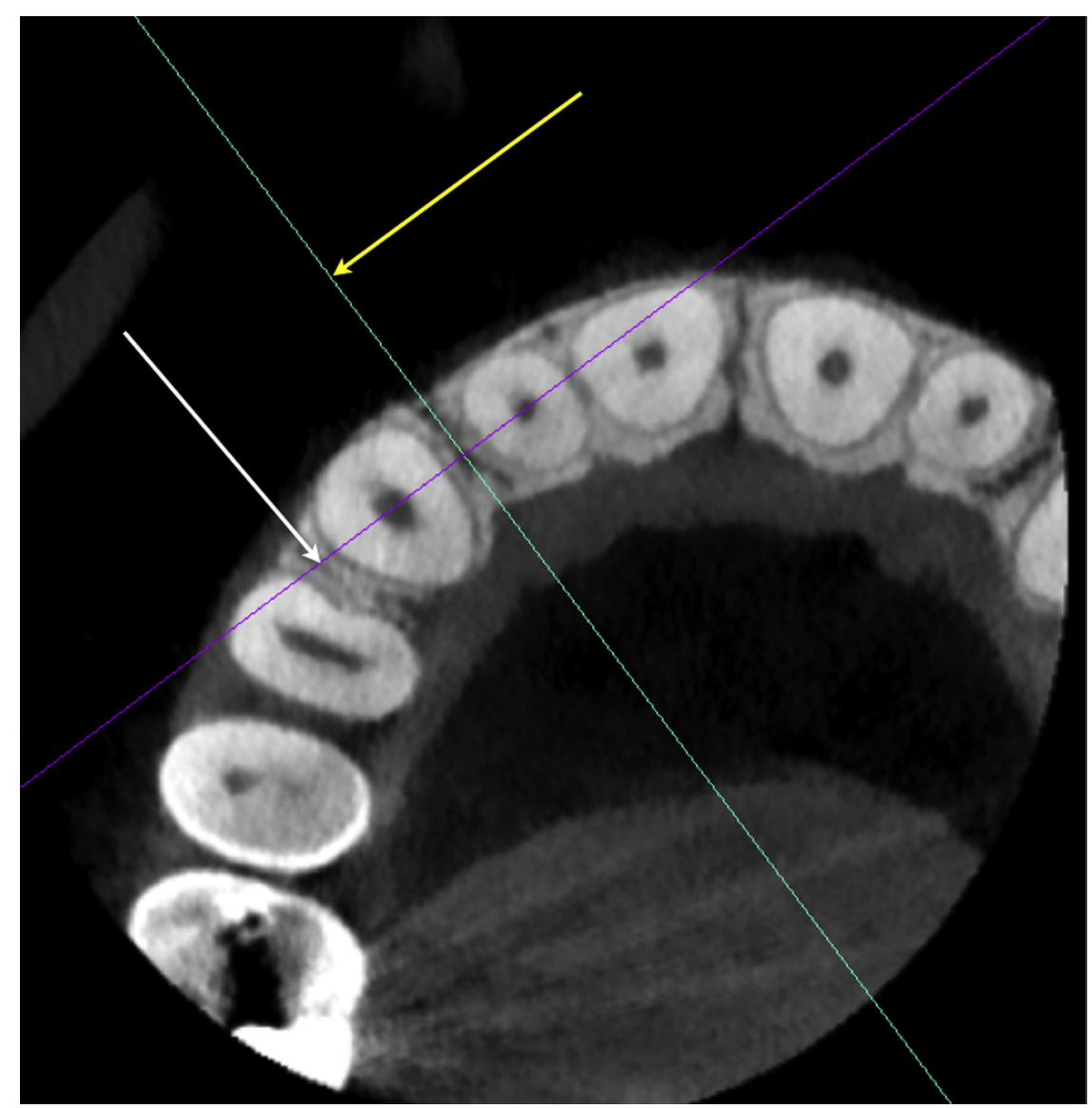

FIGURE 2. For the axial section, the horizontal line is positioned through the root canal of the lateral incisor and the canine (white arrow) and a vertical line is placed between these 2 teeth (yellow arrow).

Rodrigues et al. CBCT to Evaluate Maxillary Interdental Osteotomies. J Oral Maxillofac Surg 2018.

after surgery, a generalized linear model was adjusted that also included the patient's age and gender. To evaluate, within each group, whether the crest height after surgery is related to the crest height and inter-radicular distance before surgery, a linear regression model, with the stepwise method, was adjusted and also included the patient's age at the surgery and the time elapsed between T0 and T2.

For each group, a linear regression model was also used to evaluate the relationship between the change in crest height between $\mathrm{T} 0$ and $\mathrm{T} 2$, and the variables of inter-radicular distance at T0, change in the interradicular distance between $\mathrm{T} 0$ and $\mathrm{T} 1$, patient age at T0, and the time elapsed between T0 and T2.

\section{Results}

Of 394 patients, 82 met the inclusion criteria. A total of 246 CBCT scans were analyzed. The samples were divided into 2 groups. Group 1 underwent Le Fort I osteotomy without IDO and maxillary segmentation and included 35 patients with 105 CBCT scans. Group 2 underwent Le Fort I osteotomy with IDO for maxillary segmentation and included 47 patients and 141 CBCT scans.
To assess the reproducibility of the measurement method, 15 patients (30 interdental regions) were randomized into 2 groups, and the variable was measured with 2-day intervals between measurements. Reproducibility was measured using the intraclass correlation coefficient (ICC). It was considered that the method error can be neglected when the lower limit of the confidence interval for ICC was 0.90 or greater.

The mean patient age was 31.9 years (range 15 to 65), 66 subjects were female, and 16 were male. The patients were divided into 2 groups. Group 1 (control group) included 35 patients who had undergone maxillary osteotomy without interdental segmentation of the maxilla, with 70 interdental regions between the lateral incisors and canines and 140 teeth analyzed. Group 2 included 47 patients who had undergone maxillary osteotomy with IDOs for segmentation of the maxilla between the lateral incisors and canines, with 94 interdental regions and 188 teeth analyzed.

The descriptive statistics of patient age and the interval between T0 and T2 are presented in Table 1. The descriptive statistics of the inter-radicular distance 


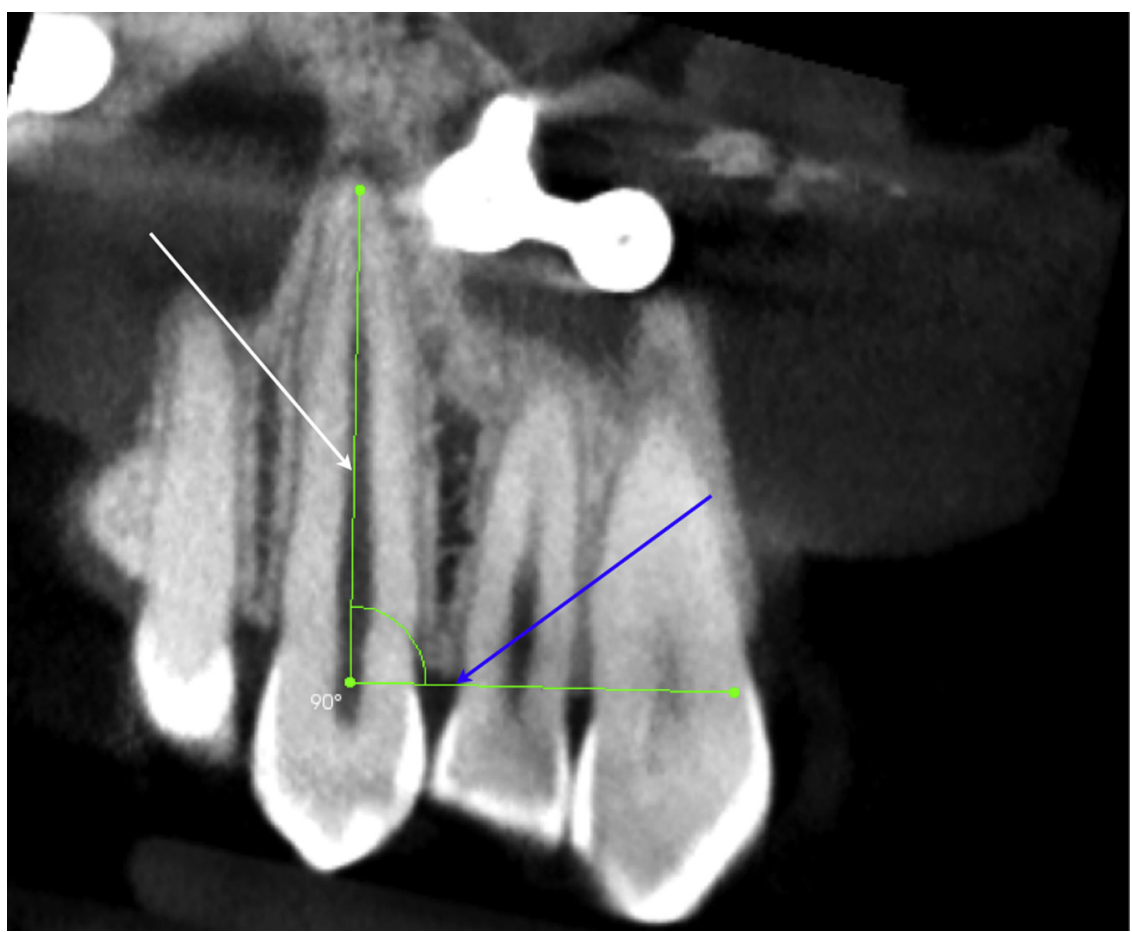

FIGURE 3. Selection of the protractor tool (green dot) is designed with an angle of $90^{\circ}$, with the vertical axis passing along the axis of the canine (white arrow) and the horizontal axis passing through the cementoenamel junction of the canine (blue arrow).

Rodrigues et al. CBCT to Evaluate Maxillary Interdental Osteotomies. J Oral Maxillofac Surg 2018.

changes are listed in Table 2. As expected, surgery with segmentation promoted statistically significant changes in this distance.
To evaluate whether changes in the crest height are related to the type of surgery and the time elapsed after surgery, an adjusted generalized linear model

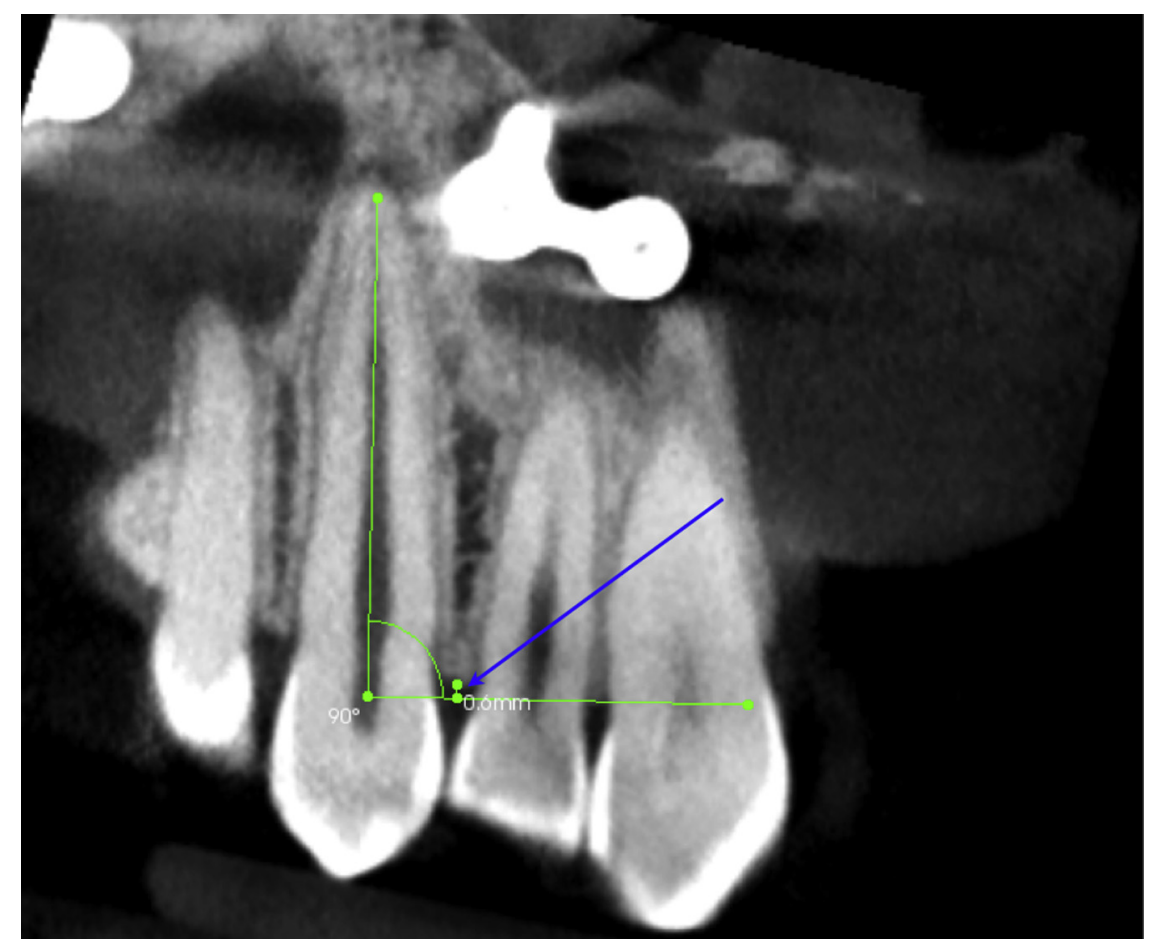

FIGURE 4. Selection of the rule function (green dot) to measure the height of the alveolar crest (in $\mathrm{mm}$ ) starting from the horizontal axis, with a line parallel to the vertical axis (blue arrow).

Rodrigues et al. CBCT to Evaluate Maxillary Interdental Osteotomies. J Oral Maxillofac Surg 2018. 


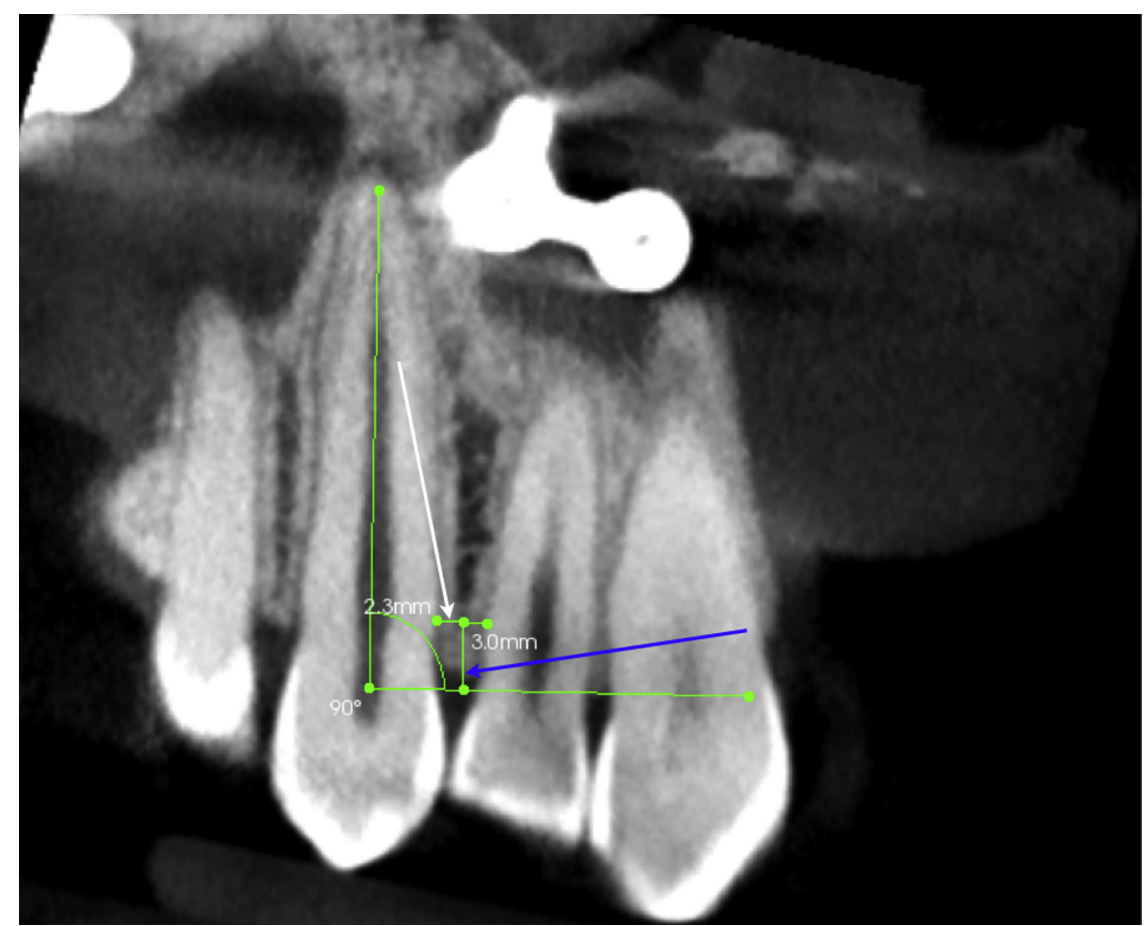

FIGURE 5. The inter-radicular distance was measured $3 \mathrm{~mm}$ above the canine cementoenamel junction (blue arrow), with a line parallel to the horizontal axis (white arrow).

Rodrigues et al. CBCT to Evaluate Maxillary Interdental Osteotomies. J Oral Maxillofac Surg 2018.

was used that also included the patient's age and gender. The analysis of variance results showed that the adjusted model was nonsignificant $(\mathrm{F}=1.52$, degrees of freedom $(\mathrm{fd})=5$ and $165, P=.186)$. Thus, no evidence was found that the type of surgery and the time elapsed after surgery can explain the possible changes at crest height. Descriptive statistics of the crest height before and after surgery and the changes occurring between T0 and T2 are listed in Table 3.

To evaluate, within each group, whether the crest height after surgery is related to the crest height and inter-radicular distance before surgery, an adjusted linear regression model, with the stepwise method, that also included patient age at surgery and the time elapsed between T0 and T2, was used. The adjusted model for the data of the group with segmentation was significant $(\mathrm{F}=15.13 ; \mathrm{fd}=2$ and 93; $P<.001 ; R^{2}=0.249$ ) and showed that the only variables that correlated with crest height at T2 were the crest height at TO and patient age. The adjusted model for the data of the group without segmentation was significant $(\mathrm{F}=28.75 ; \mathrm{fd}=3$ and 68 ; $\left.P<.001 ; R^{2}=0.559\right)$ and showed that the variables that correlated with the crest height at T2 were the crest height at T0, inter-radicular distance, and patient age (Table 4).

An adjusted linear regression model was used to evaluate the relationship between the changes on the crest

Table 1. DESCRIPTIVE STATISTICS FOR AGE AND TIME FROM TO TO T2 STRATIFIED BY GROUP AND GENDER

\begin{tabular}{lllrrrr} 
Segmentation & Gender & Variable & Minimum & Maximum & Mean & SD \\
\hline \multirow{2}{*}{ Yes } & & & & & \\
& Female $(\mathrm{n}=36)$ & Age & 15.1 & 65.7 & 31.72 & 16.56 \\
& & T2 - T0 & 11.5 & 36.1 & 18.02 & 6.00 \\
& Male $(\mathrm{n}=10)$ & Age & 18.0 & 45.2 & 27.67 & 11.48 \\
No & Female $(\mathrm{n}=30)$ & Age & 11.2 & 27.2 & 15.53 & 4.78 \\
& & T2 - T0 & 11.4 & 62.8 & 34.30 & 15.13 \\
& Male $(\mathrm{n}=6)$ & Age & 17.3 & 41.4 & 18.40 & 8.19 \\
& & T2 - T0 & 12.4 & 29.4 & 12.39 \\
\hline
\end{tabular}

Abbreviations: SD, standard deviation; T0, preoperative evaluation; T2, longest follow-up evaluation ( $\geq 11 \mathrm{mo}$ ).

Rodrigues et al. CBCT to Evaluate Maxillary Interdental Osteotomies. J Oral Maxillofac Surg 2018. 
Table 2. DESCRIPTIVE STATISTICS OF CHANGES IN INTER-RADICULAR DISTANCE (IN MM) BETWEEN TO AND TI STRATIFIED BY GENDER AND TREATMENT GROUP

\begin{tabular}{llccrr} 
Segmentation & \multicolumn{1}{c}{ Gender } & Minimum & Maximum & Mean & SD \\
\hline \multirow{2}{*}{ Yes } & Female $(\mathrm{n}=72)$ & -1.2 & 2.5 & $0.74^{*}$ & 0.67 \\
& Male $(\mathrm{n}=20)$ & -0.4 & 1.6 & $0.65^{*}$ & 0.62 \\
& Both & -1.2 & 2.5 & $0.72^{*}$ & 0.66 \\
No & Female $(\mathrm{n}=60)$ & -0.2 & 0.3 & 0.01 & 0.11 \\
& Male $(\mathrm{n}=12)$ & -0.1 & 0.2 & 0.01 & 0.11 \\
\hline
\end{tabular}

Abbreviations: SD, standard deviation; T0, preoperative evaluation; T1, immediately after surgery evaluation.

* Student $t$ test for the hypothesis that the mean equals zero $(P<.001)$.

Rodrigues et al. CBCT to Evaluate Maxillary Interdental Osteotomies. J Oral Maxillofac Surg 2018.

height between $\mathrm{T} 0$ and $\mathrm{T} 2$ and the following variables: inter-radicular distance at T0, changes in the interradicular distance between $\mathrm{T} 0$ and $\mathrm{T} 1$, patient age at T0, and the time elapsed between T0 and T2. For the segmentation group, it was not possible to fit a linear regression model because none of the considered variables correlated with the variable of interest. The adjusted model for the data from patients without segmentation was significant $(\mathrm{F}=6.25 ; \mathrm{fd}=1 \mathrm{e}$; $P=.015 ; R^{2}=0.082$ ), and the only variable related to the changes in ridge height was the inter-radicular distance before surgery. However, the coefficient value determination $\left(R^{2}\right)$ showed that even this variable explained very little, about $8 \%$, of the variability of the change in ridge height after surgery (Table 4 ). The results of analysis regarding the integrity of the teeth adjacent to the IDOs are listed in Table 5. The results of the evaluations were negative for all the variables studied.

\section{Discussion}

Maxillary segmentation involving IDOs can have an adverse effect on the interdental crestal bone and adjacent teeth. The purpose of the present study was to evaluate the effect of IDOs on surrounding osseous and dental structures, including the adjacent teeth, in patients who underwent segmental maxillary osteotomies using CBCT technology. The IDO for maxillary segmentation between the lateral incisor and canine resulted in very low morbidity for the interdental alveolar crest and the integrity of the teeth adjacent to the IDOs.

An improper surgical technique is largely responsible for the development of complications after segmental osteotomies. ${ }^{12}$ The loss of vascularization of the osteotomized segment, excessive periosteal detachment, and tears in the mucosa or attached gingiva can contribute to the complications related to bone healing at the osteotomy site. ${ }^{13,14}$ In the present study, no incisions were made in the gingival papilla, and the IDO through the alveolar crest region was performed by tunneling. We started the osteotomy started with a no. 699 burr only in the buccal cortex, complemented with a spatula osteotome through the palatal cortex. Bone grafts were placed in the bone gap if present, as suggested by Fox et $\mathrm{al}^{15}$ and Morgan and Fridrich. ${ }^{14}$

Segmentation of the maxilla should be planned in conjunction with preoperative orthodontic treatment to ensure sufficient space for the IDO, ${ }^{16}$ because root divergence is critical to the success of segmentation osteotomy. ${ }^{4,7}$ The performance of IDOs in areas with

\begin{tabular}{|c|c|c|c|c|c|}
\hline Segmentation & Gender & Minimum & Maximum & Mean & SD \\
\hline \multirow[t]{3}{*}{ Yes } & Female $(n=72)$ & -1.6 & 2.3 & $0.21^{*}$ & 0.80 \\
\hline & Male $(n=20)$ & -0.8 & 1.9 & 0.11 & 0.66 \\
\hline & Both & -1.6 & 2.3 & $0.19^{*}$ & 0.77 \\
\hline \multirow[t]{3}{*}{ No } & Female $(n=60)$ & -1.0 & 2.0 & 0.06 & 0.53 \\
\hline & Male $(n=12)$ & -0.5 & 1.2 & 0.17 & 0.53 \\
\hline & Both & -1.0 & 2.0 & 0.08 & 0.53 \\
\hline
\end{tabular}

Abbreviations: SD, standard deviation; T0, preoperative evaluation; T2, longest follow-up evaluation ( $\geq 11 \mathrm{mo})$.

* Student $t$ test for the hypothesis that the mean equals zero $(P<.05)$. 
Table 4. LINEAR ADJUSTED MODEL

\begin{tabular}{|c|c|c|c|c|c|}
\hline Segmentation & Model & $\mathrm{F}$ & $\mathrm{fd}$ & $P$ Value & $R^{2}$ \\
\hline \multicolumn{6}{|c|}{ Crest height at T2 } \\
\hline Yes & $\begin{aligned} \mathrm{CH}_{\mathrm{T} 2} & =1.05+0.34 \times \mathrm{CH}_{\mathrm{T} 0}+ \\
0.02 & \times \text { age }\end{aligned}$ & 15.13 & 2 and 93 & $<.001$ & 0.249 \\
\hline No & $\begin{array}{r}\mathrm{CH}_{\mathrm{T} 2}=1.20+0.01 \times \text { age }+ \\
0.56 \times \mathrm{CH}_{\mathrm{T} 0}+0.20 \mathrm{ID}_{\mathrm{T} 0}\end{array}$ & 28.75 & 3 and 68 & $<.001$ & 0.559 \\
\hline \multicolumn{6}{|c|}{$\begin{array}{l}\text { Change in crest height between } \\
\text { T0 and T2 }\end{array}$} \\
\hline Yes & & NS & NS & NS & NS \\
\hline No & $\begin{array}{l}\mathrm{CH}_{\mathrm{T} 2}-\mathrm{CH}_{\mathrm{TO}}=0.515- \\
\quad 0.20 \times \mathrm{ID}_{\mathrm{To}}\end{array}$ & 6.25 & 1 and 71 & .015 & .082 \\
\hline
\end{tabular}

Abbreviations: $\mathrm{CH}=$ crestal height; $\mathrm{CH}_{\mathrm{TO}}$, crestal height at T0; $\mathrm{F}$, calculated value for the adjusted model test; fd, degrees of freedom; ID, inter-radicular distance; $\mathrm{ID}_{\mathrm{TO}}$, inter-radicular distance at T0; NS, not significant; $\mathrm{R}^{2}$, determination coefficient; T0, preoperative evaluation; T1, immediate postoperative evaluation; T2, longest follow-up evaluation ( $\geq 11 \mathrm{mo}$ ).

Rodrigues et al. CBCT to Evaluate Maxillary Interdental Osteotomies. J Oral Maxillofac Surg 2018.

a narrow inter-radicular space is a risk factor for bone loss. ${ }^{17}$ In the present study, all patients had undergone orthodontic treatment preoperatively, which allowed for root divergence. The average inter-radicular distance preoperatively in group 2 (treatment group) was $2.5 \mathrm{~mm}$, and a linear regression model was adjusted to evaluate whether the crest height after surgery was related to the crest height and inter-radicular distance before surgery. The adjusted model of the group with segmentation was significant and showed that the only variables that correlated with crest height at T2 were the crest height at T0 and patient age. No correlation was found between this distance and the changes in the bone crest height (between T2 and T0), which averaged $0.19 \mathrm{~mm}$. The inter-radicular distance at To showed no correlation with damage to the adjacent teeth, the need for endodontic treatment, or tooth loss, because none of these complications developed. Thus, we have concluded that an IDO of $2.5 \mathrm{~mm}$ is sufficient to prevent damage to the teeth adjacent to

\section{Table 5. ASSESSMENT OF ROOT LESION (T1), END- ODONTIC TREATMENT (T2), AND TOOTH LOSS (T2) ON ADJACENT TEETH TO TARGETED SITE}

\begin{tabular}{|c|c|c|}
\hline \multirow[b]{2}{*}{ Measurement } & \multicolumn{2}{|c|}{ Segmentation } \\
\hline & $\begin{array}{c}\text { Yes } \\
(\mathrm{n}=188 \text { Teeth })\end{array}$ & $\begin{array}{c}\text { No } \\
(\mathrm{n}=140 \text { Teeth })\end{array}$ \\
\hline Root lesion (T1) & Absent & Absent \\
\hline Endodontics (T2) & Absent & Absent \\
\hline Tooth loss (T2) & Absent & Absent \\
\hline
\end{tabular}

Abbreviations: T1, baseline; T2, longest follow-up evaluation.

Rodrigues et al. CBCT to Evaluate Maxillary Interdental Osteotomies. J Oral Maxillofac Surg 2018. the osteotomy and avoid the complications related to loss of the marginal bone crest.

The clinical and radiographic evaluation by Fox et $\mathrm{al}^{15}$ of segmented maxillary osteotomies showed an increased inter-radicular distance that was statistically significant. They found no statistically significant changes in the height of the alveolar bone support. In the present study, the group with segmentation showed a statistically significant increase in the interradicular distance, which averaged $0.72 \mathrm{~mm}$. When correlating this increase in the inter-radicular distance (between T1 and T0) with the change in the height of bone crest (between T2 and T0) of averaging $0.19 \mathrm{~mm}$, it was not possible to fit a linear regression model because none of the considered variables correlated with the variable of interest. Thus, the increase in the inter-radicular distance did not influence the crest height at a minimum of 11 months after surgery.

The complications associated with IDOs are generally rare when the treatment has been designed properly with a proper surgical technique. ${ }^{16}$ Some studies evaluated segmentation osteotomies of the maxilla and mandible together. ${ }^{13,18}$ Others have evaluated jaw segmentation associated with dental extractions performed during surgery. ${ }^{19,20}$ Several studies have shown a decrease in the height of the marginal bone crest after segmentations: $1.6,{ }^{21} 1,{ }^{17}$ and $0.5 \mathrm{~mm} .{ }^{16}$ In the present study, the evaluation of the segmentation region was performed only in the maxilla and interdental space without teeth extractions. This resulted in a smaller region in which to perform the osteotomies, which could have increase the risk of complications. All the osteotomies were made in the same region (between the lateral incisor and canine). The bone crest height decreased an average of $0.19 \mathrm{~mm}, \quad$ a statistically significant difference $(P<.05)$. However, changes of this magnitude are 
clinically irrelevant. ${ }^{15}$ This vertical change could have resulted, in part, to the vertical positional changes of the anterior segment relative to the posterior segments as applied for closure of anterior open bites.

Kwon et $\mathrm{al}^{17}$ and Schou et $\mathrm{al}^{16}$ used areas without segmentation of the same patient as the control group, making it impossible to assess the same region. In our study, the control group included patients who had undergone only Le Fort I osteotomy without segmentation. This allowed us to assess the same region in both groups: the region between the lateral incisor and canine. Schou et $\mathrm{al}^{16}$ compared the marginal bone loss in 2 groups, with and without interdental segmentation, and found no statistically significant difference. Corroborating the findings of these investigators, when we compared groups 1 and group 2, we found no statistically significant differences in the change in the height of the bone crest. However, the inter-radicular distance in group 2 (segmentation group) increased compared with the control group (without segmentation) and resulted in a statistically significant difference (average $0.72 \mathrm{~mm}$ ). This was as expected, because in group 2 with segmentation, the preoperative orthodontic directions, including tipping the canine roots distally and lateral incisor roots mesially, correction for tooth size discrepancy, and tipping the anterior segment to upright the incisors, usually promoted an increased interradicular distance.

Intraoral radiographs are commonly used in clinical practice to assess the depth of bone defects; however, only 2 dimensions will be visible. ${ }^{22,23}$ Details of the structures sometimes cannot be visualized because of overlap of the teeth and interference from the braces. CT scans allow for an anatomic image of the bone structure in the 3 planes of space, without distortion. However, the present study had some deficiencies, including no clinical evaluation performed regarding the periodontal aspect.

In conclusion, according to the results obtained in the present study, an approximate preoperative inter-radicular distance of $2.5 \mathrm{~mm}$ will be sufficient to prevent damage to the teeth adjacent to the osteotomy and avoid complications related to loss of the marginal bone crest. In addition, the change in the height of the bone crest in group 2, who underwent IDO, was, on average, $0.19 \mathrm{~mm}$. The inter-radicular distance of the adjacent teeth in group 2 (IDO group) increased an average of $0.72 \mathrm{~mm}$ compared with that in group 1 and showed no correlation with the change in the height of the bone crest. Finally, performing the maxillary interdental segmental osteotomy between the lateral incisor and canine, using an appropriate technique, resulted in reduced morbidity related to the decrease in the alveolar bone crest and integrity of the adjacent teeth at the IDO sites.

\section{References}

1. Shawky M, El-Ghareeb L, Hameed Abu Hummus LA: Evaluation of the three-dimensional soft tissue changes after anterior segmental maxillary osteotomy. Int J Oral Maxillofac Surg 41: 718,2012

2. Kahnberg KE, Hagberg C: The approach to dentofacial skeletal deformities using a multisegmentation technique. Clin Plastic Surg 34:477, 2007

3. Ho MW, Boyle MA, Cooper JC, et al: Surgical complications of segmental Le Fort I osteotomy. Br J Oral Maxillofac Surg 49: 562,2011

4. Arpornmaeklong P, Heggie AA, Shand JA: A comparison of the stability of single-piece and segmental Le Fort I maxillary advancements. J Craniofac Surg 14:3, 2003

5. Wolford LM, Alexander CM, Stevao ELL, et al: Orthodontics for orthognathic surgery, in Michael M, Ghali GE, Larsen PE, Waite PD (eds): Principles of Oral and Maxillofacial Surgery (ed 4). Shelton, CT, People's Medical Publishing House, 2012, pp 1263-1264

6. Kahnberg KE, Vannas-Lofqvist L, Zellin G: Complications associated with segmentation of the maxilla: A retrospective radiographic follow up of 82 patients. Int J Oral Maxillofac Surg 34: 840,2005

7. Wolford LM, Rieche-Fischel O, Mehra P: Soft tissue healing after parasagittal palatal incisions in segmental maxillary surgery: A review of 311 patients. J Oral Maxillofac Surg 60:20, 2002

8. Venugoplan SR, Nanda V, Turkistani K, et al: Discharge patterns of orthognathic surgeries in United States. J Oral Maxillofac Surg 70:e77, 2012

9. Wolford LM, Movahed R: Combined TMJ and orthognathic surgery, in Kademani D, Tiwana P (eds): Atlas of Oral and Maxillofacial Surgery. Philadelphia, PA, Elsevier Saunders, 2016, pp 1364-1377

10. Wolford LM: Surgical planning in orthognathic surgery, in Booth PW, Schendel SA, Hausamen JE (eds): Maxillofacial Surgery, Vol. 2. St. Louis, MO, Churchill Livingstone, 2007, pp 1155-1210

11. Guymon M, Crosby DR, Wolford LM: The alar base cinch suture to control nasal width in maxillary osteotomies. Int J Adult Orthod Orthognath Surg 2:89, 1988

12. Wolford LM: Periodontal disease associated with interdental osteotomies after orthognathic surgery-Discussion. J Oral Maxillofac Surg 56:414, 1998

13. Sher MR: A survey of complications in segmental orthognathic surgical procedures. Oral Surg Oral Med Oral Pathol 58:537, 1984

14. Morgan TA, Fridrich KL: Effects of the multiple-piece maxillary osteotomy on the periodontium. Int J Adult Orthodon Orthognath Surg 16:255, 2001

15. Fox ME, Stephens WF, Wolford LM, El Deeb M: Effects of interdental osteotomies on the periodontal and osseous supporting tissues. Int J Adult Orthodon Orthognath Surg 6:39, 1991

16. Schou S, Vedtofte P, Nattestad A, Stoltze K: Marginal bone level after Le Fort I osteotomy. Br J Oral Maxillofac Surg 35:153, 1997

17. Kwon H, Pihlstrom B, Waite D: Effects on the periodontium of vertical bone cutting for segmental osteotomy. J Oral Maxillofac Surg 43:952, 1985

18. Schultes G, Gaggl A, Karcher H: Periodontal disease associated with interdental osteotomies after orthognathic surgery. J Oral Maxillofac Surg 56:414, 1998

19. Dorfman HS, Turvey TA: Alterations in osseous crestal height following interdental osteotomies. Oral Surg Oral Med Oral Pathol 48:120, 1979

20. Laningan DT, Hey JH, West RA: Aseptic necrosis following maxillary osteotomies: Report of 36 cases. J Oral Maxillofac Surg 48: 142,1990

21. Rosenquist R: Anterior segmental maxillary osteotomy. Int J Oral Maxillofac Surg 22:210, 1993

22. Misch KA, Sarment DP: Accuracy of cone beam computed tomography for periodontal defect measurements. J Periodontol $77: 1261,2006$

23. Grimard BA, Hoidal MJ, Mills MP, et al: Comparison of clinical, periapical radiograph, and cone beam volume tomography measurement technique for assessing bone level changes following regenerative periodontal therapy. J Periodontol 80:48, 2009 